\title{
Genetic parameter estimates for temperament, heifer rebreeding, and stayability in Nellore cattle
}

\author{
T.S. Valente ${ }^{a}$, O.D. Albito ${ }^{a}$, A.C. Sant'Anna ${ }^{\mathrm{b}}$, R. Carvalheiro ${ }^{\mathrm{a}, \mathrm{c}}, \mathrm{F}$. Baldi $^{\mathrm{a}, \mathrm{c}}$, L.G. Albuquerque ${ }^{\mathrm{a}, \mathrm{c}}$, \\ M.J.R. Paranhos da Costa ${ }^{a, c, *}$

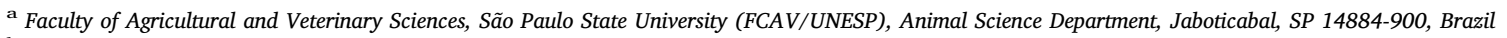 \\ b Federal University of Juiz de Fora/UFJF - Zoology Dept., Juiz de Fora, MG 36036-900 Brazil \\ c National Council for Scientific and Technological Development (CNPq), Brazil
}

\section{A R T I C L E I N F O}

\section{Keywords:}

Longevity

Flight speed test

Genetic correlation

Reactivity

Reproductive traits

\begin{abstract}
A B S T R A C T
The aim of this study was to estimate heritability for five temperament and two reproductive traits in Nellore cattle and to estimate genetic and phenotypic correlations among them. Temperament was evaluated using the movement (MOV), tension (TEN) and crush (CS) scores (measured with animals inside the squeeze chute) as well as the flight speed (FS) and temperament score (TS). Reproductive traits included $i$ ) heifer rebreeding (HR), which evaluates heifers' ability to become pregnant, given that they had calved once; and ii) stayability (STAY), which measures cows' ability to calve at least 3 offspring before reaching 65 months of age. We used Bayesian inference and Gibbs sampling in a two-trait analysis to estimate genetic parameters applying a linear model for FS and threshold models for MOV, TEN, CS, TS, HR and STAY. The animal model included contemporary group as a fixed effect, direct additive genetic and residual effects as random effects, and animal age at yearling as a covariate (with linear and quadratic effects). Heritability estimates for MOV, TEN, CS, FS, TS, HR and STAY were $0.14 \pm 0.04,0.11 \pm 0.03,0.09 \pm 0.03,0.22 \pm 0.02,0.19 \pm 0.04,0.13 \pm 0.02$ and $0.13 \pm 0.02$, respectively The genetic correlation estimates were low to moderate and the highest values (in magnitude) were $0.19 \pm 0.21$ (HR-CS), $-0.21 \pm 0.15$ (STAY-TEN) and $-0.24 \pm 0.16$ (STAY-CS), indicating that the selection to improve cattle temperament does not negatively affect HR and STAY. These results indicate that all traits had sufficient genetic variability to respond to direct selection; however, given the low estimated heritability, we expect to see only long-term genetic changes. Genetic correlations showed that there is no antagonism of temperament with fertility and longevity; however, we recommend including these traits as selection criteria in Nellore breeding programs to obtain satisfactory genetic changes.
\end{abstract}

\section{Introduction}

Cattle temperament has been recognized as an important trait for the cattle industry due to its relationship with productive and reproductive performance, labor accidents and animal welfare (Haskell et al., 2014). Several breeding programs are currently using distinct standardized indicators as selection criteria to improve cattle temperament. Using these indicators requires a broad understanding of the genetic and phenotypic associations of cattle temperament with traits that are economically important for beef production (Haskell et al., 2014; Sant'Anna et al., 2015).

Reproductive traits have received special attention in beef cattle breeding programs due to their economic impact, especially on cow-calf operations (Van Melis et al., 2007). Thus, several reproductive traits have been used as selection criteria to improve cows' fertility, sexual precocity, stayability and maternal ability (Valente et al., 2015; White et al., 2016). Previous studies have reported low to moderate heritability (ranging from $0.12 \pm 0.04$ to $0.28 \pm 0.03$ ) for traits associated with Nellore cow longevity, such as stayability (Silva et al., 2003; Van Melis et al., 2007; Guarini et al., 2015). Another important indicator of female persistence is heifer reconception. In commercial enterprises, Mercadante et al. (2003) reported a $20 \%$ reduction in conception rate from the first to the second breeding season, and primiparous cows that fail to reconceive during their second breeding season are often culled. In general, estimated heritabilities for heifer rebreeding in Nellore herds are low $(0.10 \pm 0.07,0.18 \pm 0.02$ and $0.15 \pm 0.00)$, as reported by Mercadante et al. (2003), Boligon et al. (2012) and Guarini et al. (2015), respectively.

The relationship between temperament and reproductive traits has been explored at the phenotypic level, with several studies

\footnotetext{
* Corresponding author at: Faculty of Agricultural and Veterinary Sciences, São Paulo State University (FCAV/UNESP), Animal Science Department, Jaboticabal, SP 14884-900, Brazil.

E-mail address: mpcosta@fcav.unesp.br (M.J.R. .da Costa).
} 
Table 1

Description of the methods used to assess temperament of Nellore cattle.

\begin{tabular}{|c|c|c|}
\hline Trait & Description & Scale \\
\hline $\begin{array}{l}\text { Movement score } \\
\quad \text { (MOV) }\end{array}$ & $\begin{array}{l}\text { Assessed the movement of the animals inside the squeeze chute (crush) } \\
\text { for } 4 \mathrm{~s} \text {, just after its entrance (as described by Sant'anna et al., 2013) }\end{array}$ & $\begin{array}{l}\text { 1. no movement } \\
\text { 2. little movement, during less than half of the observation time } \\
\text { 3. frequent movements (during half of the observation time or more), but not } \\
\text { vigorous } \\
\text { 4. constant and vigorous movements } \\
\text { 5. constant and vigorous movements, animal jumps and raises its forelimbs } \\
\text { off the ground }\end{array}$ \\
\hline Tension score (TEN) & $\begin{array}{l}\text { Assessed the cattle overall body tension, and head, ear and tail } \\
\text { movements scoring }\end{array}$ & $\begin{array}{l}\text { 1. the animal did not exhibit sudden movements of the tail, head, and } \\
\text { neck, no muscle tremors, and white of eye was not visible } \\
\text { 2. the animal exhibited few sudden movements of the tail, head, and neck, } \\
\text { no muscle tremors, and white of eye was visible or not } \\
\text { 3. the animal exhibited continuous and vigorous movements of the tail, head } \\
\text { and neck, white of eye was visible, no muscle tremors } \\
\text { 4. the animal appeared paralyzed or "freezing" reaction, muscle tremors } \\
\text { were visible }\end{array}$ \\
\hline Crush score (CS) & $\begin{array}{l}\text { Assessed the cattle overall reactivity inside the squeeze chute (as } \\
\text { described by Sant'anna et al., 2013) }\end{array}$ & $\begin{array}{l}\text { 1. the animal does not offer resistance, remains with head, ears and tail } \\
\text { relaxed } \\
\text { 2. some movement, with head and ears rising up } \\
\text { 3. frequent movement but not vigorous, head, ear and tail movements, sclera } \\
\text { of the eye (eye white) may be visible } \\
\text { 4. offers great resistance, abrupt and vigorous movements of the whole } \\
\text { animal as well as the head, ear and tail, sclera of the eye visible, audible } \\
\text { breathing and may jump or fall } \\
\text { 5. the animal offers or not great resistance, sclera of the eye is always visible } \\
\text { and has a 'freezing' reaction }\end{array}$ \\
\hline Flight speed (FS) & $\begin{array}{l}\text { Measured the speed at which the animal leaves the crush after being } \\
\text { weighed (Burrow et al., 1988) }\end{array}$ & $\begin{array}{l}\text { This measurement was taken using an electronic device that records the } \\
\text { time (s) taken by each animal to cover a known distance (which ranged } \\
\text { from } 1.6 \text { to } 2.0 \mathrm{~m} \text {, depending on the facilities), later converted to speed (m/ } \\
\text { s). The faster animals were considered as presenting more excitable } \\
\text { temperament. }\end{array}$ \\
\hline $\begin{array}{l}\text { Temperament score } \\
\text { (TS) }\end{array}$ & $\begin{array}{l}\text { Assessed the reaction of the animals in a pen of the corral. To avoid the } \\
\text { tendency of the evaluators to concentrate the grades in the intermediary } \\
\text { level }(\mathrm{TS}=3 \text { ), the intermediate grade was removed from the scale } \\
\text { (DeltaGen, 2016) }\end{array}$ & $\begin{array}{l}\text { 1. the animal walks slowly, allowing proximity to the observer } \\
\text { 2. trots or runs for a few seconds, allowing a moderate proximity to the } \\
\text { observer } \\
\text { 3. runs during the entire observation time, looking for an escape with } \\
\text { constant movement of the tail, and does not allow close or moderate } \\
\text { proximity } \\
\text { 4. runs during the entire time of the assessment, jumps against fences and } \\
\text { obstacles, and tries to attack the observer }\end{array}$ \\
\hline
\end{tabular}

demonstrating that excitable temperament is detrimental to pregnancy rates (Kasimanickam et al., 2014; Rueda et al., 2015; White et al., 2016). Some studies also report genetic correlations between distinct temperament and reproductive traits (Burrow, 2001; Phocas et al., 2006; Barrozo et al., 2012; Valente et al., 2015). Genetic correlation values vary widely across these studies (from -0.44 to 0.55 ), which probably reflects the use of different breeds, sample sizes and phenotypic traits to measure temperament and reproductive performance. There is also a lack of studies reporting genetic correlations among temperament and reproductive traits related to cow longevity and heifer rebreeding, two parameters that are important for defining selection strategies in Nellore breeding programs. Thus, the aim of this study was to estimate heritability for five temperament and two reproductive (heifer rebreeding and stayability) traits in Nellore cattle and to estimate the genetic and phenotypic correlations among them.

\section{Material and methods}

No approval was required from the Committee for the Ethical Use of Animals for the present study, because all records came from an existing database and did not involve any experiments or procedures with the animals. Temperament evaluations were carried out during the regular handling routines, when the animals were weighed at yearling age. Temperament data were collected at Agropecuária Jacarezinho ${ }^{\circledast}$ Ltda (AJ), which is specialized in the selection and breeding of Nellore cattle raised under an extensive system where the animals are maintained on tropical pastures with free access to water and mineral supplements throughout the year. DeltaGen breeding program provided the reproductive dataset.

The AJ conducts two breeding seasons that aim to identify and select sexually precocious heifers. The early season occurs from February to April, lasts approximately 60 days, and only 14- to 16-month-old heifers are exposed to bulls (proportion of 1:30). Heifers that fail to conceive during this first season are exposed to bulls once again at 2 years of age. The second season takes place between November and January and lasts 70 days for multiparous females and 60 days for heifers using fixed time artificial insemination. Females that do not get pregnant through artificial insemination then undergo natural mating with controlled or multiple-sire breeding. Pregnancy is confirmed approximately 60 days after the end of each breeding season.

After birth, cow-calf pairs are assigned to handling groups by calf sex. At approximately 210 days of age, the calves are weighed, assessed for visual scores (conformation, finishing precocity and muscling) and weaned. These scores are entered into a selection index that helps identify animals that will remain in the herd based on their phenotype. Selected animals are relocated to new handling groups, where they remain until they reach approximately 550 days of age (yearling). At yearling, a second performance evaluation is conducted that includes measurements of scrotal circumference, weight, breed characteristics and temperament. Based on weaning and yearling age information, a new selection index is calculated and $50 \%$ of males and $10 \%$ of females are culled (DeltaGen, 2016). Independent culling is applied in animals with the worst breed characteristics and temperament scores. Also, the criteria for female culling are failure to conceive before 2 years of age and failure to reconceive in any consecutive season. 


\subsection{Temperament assessments}

Temperament was assessed during the handling procedures for performance evaluation at yearling age in order to minimize interference with the farm routine. All evaluations were performed from 2010 to 2014 and assessed five temperament traits: movement score (MOV), tension score (TEN), crush score (CS), flight speed (FS) and temperament score (TS). The AJ adopted the TS as a selection criterion from 2004 to 2014 and applied the method of independent culling levels, which excludes individuals that receive a score of 5 (very excitable and aggressive temperament). The full description of these methods is shown in Table 1.

\subsection{Reproductive traits}

The reproductive dataset of animals born between 1990 and 2013 included information about heifer rebreeding (HR) and stayability (STAY). As mentioned above, HR measures the ability of heifers that have calved once to become pregnant, and is scored in a binary way: 1 $=$ heifers that fail, and $2=$ heifers that succeed at getting pregnant after their first calving. Stayability (STAY) represents cow longevity and is defined as a cow's ability to remain in the herd at least 65 months and to calve at least three times. The criterion of three calves until 65 months was established based on the fact that this number of calves and time frame are enough to cover each cow's breeding and rebreeding costs (Van Melis et al., 2007). Stayability (STAY) is also a binary trait (i.e., 1 = failure and 2 = success). For the STAY analyses, we only included animals born before 2009 to ensure the inclusion of cows that had been in the herd for 65 months and potentially calved at least three times. Score frequencies for all categorical traits are shown in Table 2.

\subsection{Statistical analysis}

For temperament traits, contemporary groups (CG) were comprised by sex, farm and year of birth, management groups at birth, at weaning and at yearling. For HR and STAY, the CG consisted of farm and year of birth, management group at yearling and cow sexual precocity classification (a binary trait defined by the ability to calve for the first time before 30 months of age). Only for HR, the CG also included calf sex, year and season of birth, as well as management group during the first offspring's weaning. The number of precocious heifers was 4426 (13.45\% of the total) and there were $28,493(86.55 \%)$ non-precocious ones. Season was categorized as 'rainy' from October to March and 'dry' from April to September. For all traits, CG with fewer than three animals and no variability (all animals had the same score) were not included in the analyses. For FS, records outside the range (i.e., CG mean \pm 3 SDs) were also excluded from the analyses. The descriptive statistics for temperament and reproductive traits are summarized in Table 3. The pedigree file included 61,292 animals with 1231 bulls and 32,503 dams.

The (co)variance components and genetic parameters were estimated with Bayesian Inference using Gibbs sampling algorithm implemented in the THRGIBBS1F90 software (Misztal et al., 2002). Twotrait analyses were performed considering one temperament and one
Table 3

Number of records, means \pm standard deviation, medians, number of CG, numbers of sires and dams for movement score (MOV), tension score (TEN), crush score (CS), flight speed (FS), temperament score (TS), heifer rebreeding (HR) and stayability (STAY) measured in Nellore cattle.

\begin{tabular}{lllllll}
\hline Traits & $\begin{array}{l}\text { Number of } \\
\text { records }\end{array}$ & Mean \pm SD & Median & CG $^{\text {a }}$ & $\begin{array}{l}\text { Number of } \\
\text { sires }\end{array}$ & $\begin{array}{l}\text { Number of } \\
\text { dams }\end{array}$ \\
\hline MOV & 16,874 & - & 2 & 706 & 746 & 12,302 \\
TEN & 16,863 & - & 2 & 704 & 746 & 12,297 \\
CS & 16,860 & - & 3 & 704 & 746 & 12,289 \\
FS (m/s) & 16,801 & $2.35 \pm 1.04$ & - & 708 & 740 & 12,293 \\
TS & 15,599 & - & 2 & 853 & 666 & 11,500 \\
HR & 29,737 & - & 2 & 1152 & 641 & 19,049 \\
STAY & 30,528 & - & 1 & 267 & 515 & 18,911 \\
\hline
\end{tabular}

${ }^{\mathrm{a}} \mathrm{CG}=$ contemporary group

reproductive trait simultaneously. The number of animals with both temperament and reproductive phenotypes were: 2909 (HR-MOV), 2905 (HR-TEN), 2902 (HR-CS), 2885 (HR-FS), 6939 (HR-TS), 2036 (STAY-MOV), 2035 (STAY-TEN), 2029 (STAY-CS), 2027 (STAY-FS) and 6043 (STAY-TS). Threshold models were adopted for MOV, TEN, CS, TS, HR and STAY and a linear model was used for FS. The Bayesian threshold is an appropriate method for conducting genetic analyses of categorical traits, assuming that the levels of categorical variables are related to an underlying continuous scale containing fixed and random effects (Van Tassell et al., 1998).

The model included direct additive genetic and residual effects as random effects and CG as a fixed effect. Animal age at the time of measurement and at first calving were included as covariates for temperament (with linear and quadratic effects) and reproductive (with linear effect) traits, respectively. The matrix presentation of the general model used is:

$y=X \beta+\mathrm{Za}+e$

where $\boldsymbol{y}$ is the vector of observations; $\boldsymbol{\beta}$ is the vector of fixed effects; $\boldsymbol{a}$ is the vector of direct additive genetic effects; $\boldsymbol{e}$ is the vector of residual effects; and $\boldsymbol{X}$ and $\boldsymbol{Z}$ are incidence matrices relating $\boldsymbol{\beta}$ and $\boldsymbol{a}$ to $\boldsymbol{y}$. It was assumed that $\mathrm{E}[y]=X \beta ; \operatorname{Var}(a)=A \otimes G ; \operatorname{Var}(e)=I \otimes R$, where $A$ is the relationship matrix among all animals in the pedigree file, $\otimes$ is the direct product, $\boldsymbol{G}$ is the (co)variance matrix of direct additive genetic effects, $\boldsymbol{I}$ is the identity matrix and $\boldsymbol{R}$ is the (co)variance matrix of residual effects.

The vectors $\boldsymbol{\beta}$ and $\boldsymbol{a}$ are location parameters from the conditional distribution. A uniform distribution of $\boldsymbol{\beta}$ was assumed a priori, which reflects a vague prior knowledge about this vector. For (co)variance matrices of random effects, inverted Wishart distributions were defined as prior distributions. Thus, the distribution of $\boldsymbol{y}$ given the parameters of location and scale was assumed (Van Tassell and Van Vleck, 1996):

\section{$y \mid \boldsymbol{\beta}, a, R \sim \mathrm{MVN}\left[X \boldsymbol{\beta}+\mathrm{Za}, \boldsymbol{I}_{\boldsymbol{N}} \boldsymbol{R}\right]$}

In the two-trait analyses, chains of 800,000 iterations were generated, with samplings every 100 cycles. The first 25,000 iterations were discarded as fixed burn-in. Thus, 7750 samples were used for parameter estimation. Data convergence was checked through graphical analysis,

Table 2

Sample size and percentage of animals in each categorical temperament (MOV, TEN, CS and TS) and reproductive trait (HR and STAY) assessed in the study.

\begin{tabular}{lllllll}
\hline Score & MOV $(N=16,874)$ & TEN $(N=16,863)$ & CS $(N=16,860)$ & TS $(N=15,599)$ & HR $(N=29,737)$ & STAY $(N=30,528)$ \\
\hline 1 & $28.5 \%$ & $16.7 \%$ & $4.20 \%$ & $9.2 \%$ & $29.2 \%$ & $58.4 \%$ \\
2 & $33.7 \%$ & $40.9 \%$ & $35.50 \%$ & $84.6 \%$ & $70.8 \%$ & $41.6 \%$ \\
3 & $23.7 \%$ & $39.6 \%$ & $43.10 \%$ & - & - & - \\
4 & $10.4 \%$ & $2.9 \%$ & $15.20 \%$ & $6.1 \%$ & - & - \\
5 & $3.7 \%$ & - & $2.10 \%$ & $0.1 \%$ & - & - \\
\hline
\end{tabular}

MOV = movement score; TEN = tension score; $\mathrm{CS}=$ crush score; $\mathrm{TS}=$ temperament score; $\mathrm{HR}=$ heifer rebreeding; STAY $=$ stayability 

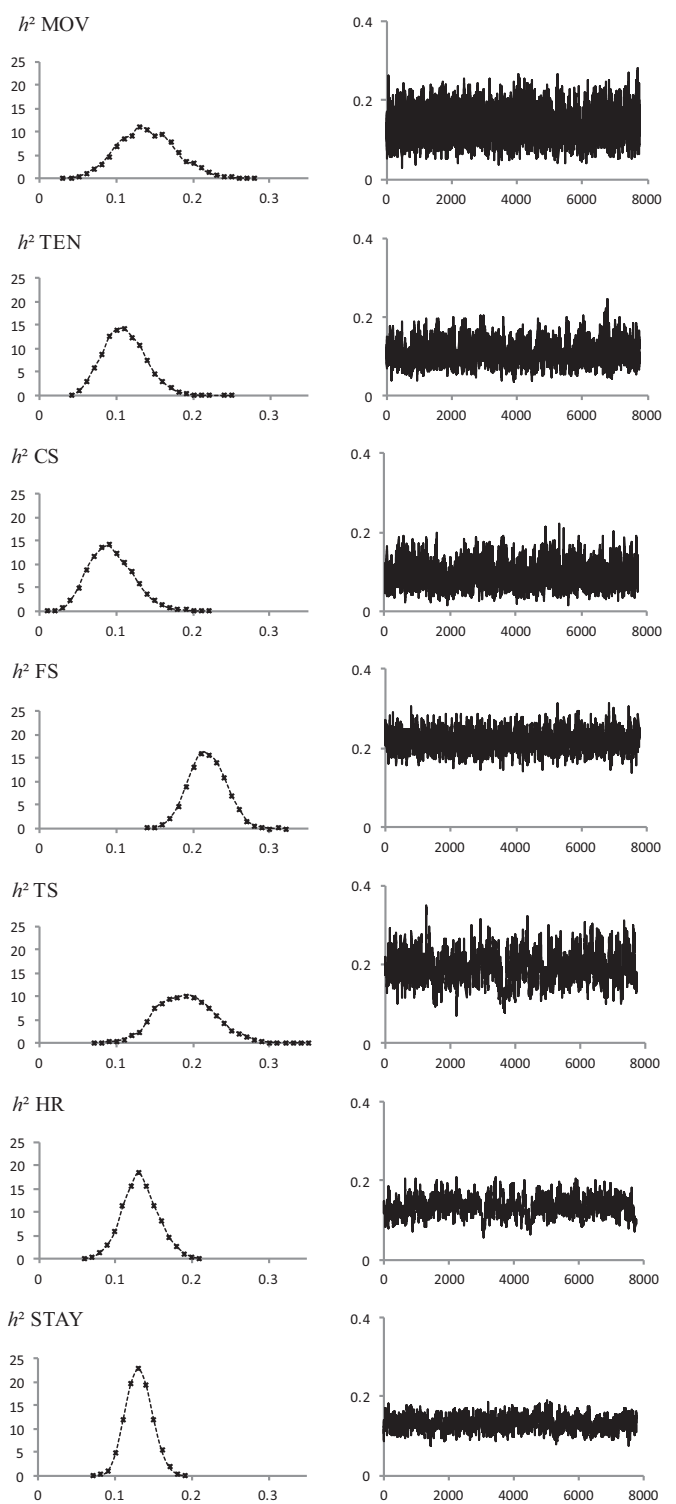

Fig. 1. Posterior density (A) and trace plots (B) of heritability $\left(\mathrm{h}^{2}\right)$ estimates for movement score (MOV), tension score (TEN), crush score (CS), flight speed (FS), temperament score (TS), heifer rebreeding (HR) and stayability (STAY) in Nellore cattle.

sampled values versus rounds and the criteria proposed by Geweke (1992), Heidelberger and Welch (1983) and Raftery and Lewis (1992) using the R software, with the Bayesian Output Analysis (BOA) package in R 2.9.0 software (The R Development Core Team 2009).

\section{Results and discussion}

According to the convergence criteria applied in this study, the number of cycles (8000), fixed burn-in periods ( 250 cycles) for all twotrait analyses and the number of remaining Markov chains (7750) were adequate for obtaining the convergence of all parameters estimated. The posterior density and trace of heritability estimated for MOV, TEN, CS, FS, TS, HR and STAY are shown in Fig. 1. The distribution of each chain remained stable, allowing for chain convergence (Gelfand and Smith, 1990), which was achieved with low SD and a relatively short 95\% highest posterior density interval (HPD). Table 4 shows the posterior means of heritability, additive genetic and residual variances obtained with each of the two-trait analyses.

The posterior means of heritability for all temperament traits ranged
Table 4

Descriptive statistics of a posterior density [95\% highest posterior density intervals] of variance components and heritability $\left(\mathrm{h}^{2}\right)$ estimates for temperament (MOV, TEN, CS, FS and TS) and reproductive (HR and STAY) traits.

\begin{tabular}{llll}
\hline & $\sigma_{\mathbf{a}}^{2}$ & $\sigma_{\mathbf{e}}^{2}$ & $h^{2}$ \\
\hline MOV & $0.10 \pm 0.02$ & $0.65 \pm 0.20$ & $0.14 \pm 0.04$ \\
& {$[0.06$ to 0.14$]$} & {$[0.37$ to 1.04$]$} & {$[0.07$ to 0.22$]$} \\
TEN & $0.04 \pm 0.01$ & $0.30 \pm 0.05$ & $0.11 \pm 0.03$ \\
& {$[0.02$ to 0.05$]$} & {$[0.21$ to 0.40$]$} & {$[0.06$ to 0.16$]$} \\
CS & $0.01 \pm 0.00$ & $0.12 \pm 0.04$ & $0.09 \pm 0.03$ \\
& {$[0.01$ to 0.02$]$} & {$[0.07$ to 0.19$]$} & {$[0.04$ to 0.15$]$} \\
FS & $0.18 \pm 0.02$ & $0.64 \pm 0.02$ & $0.22 \pm 0.02$ \\
& {$[0.14$ to 0.22$]$} & {$[0.61$ to 0.68$]$} & {$[0.17$ to 0.26$]$} \\
TS & $0.02 \pm 0.00$ & $0.07 \pm 0.00$ & $0.19 \pm 0.04$ \\
& {$[0.01$ to 0.02$]$} & {$[0.06$ to 0.08$]$} & {$[0.12$ to 0.27$]$} \\
HR & $0.16 \pm 0.03$ & $1.00 \pm 0.00$ & $0.13 \pm 0.02$ \\
STAY & {$[0.10$ to 0.22$]$} & {$[1.00$ to 1.04$]$} & {$[0.09$ to 0.18$]$} \\
& $0.15 \pm 0.02$ & $1.01 \pm 0.01$ & $0.13 \pm 0.02$ \\
& {$[0.11$ to 0.20$]$} & {$[0.99$ to 1.02$]$} & {$[0.10$ to 0.16$]$} \\
\hline
\end{tabular}

$\mathrm{SD}=$ standard deviation; $\sigma_{\mathrm{a}}^{2}=$ genetic additive variance $; \sigma_{\mathrm{e}}^{2}=$ residual variance; $\mathrm{MOV}=$ movement score; TEN = tension score; $\mathrm{CS}=$ crush score; FS = flight speed; TS = temperament score; HR = heifer rebreeding; STAY = stayability.

from $0.09 \pm 0.03$ (CS) to $0.22 \pm 0.02$ (FS), and were consistent with the values previously reported for Bos-taurus, Bos-indicus and their crosses (Burrow and Corbet, 2000; Prayaga et al., 2009; Barrozo et al., 2012; Piovezan et al., 2013) and our own previous results (Sant'Anna et al., 2013, 2015; Valente et al., 2015) when using three-trait analyses with Bayesian Inference. Thus, it is expected that the use of MOV, TEN and CS as selection criteria would promote few genetic changes in cattle temperament over time. On the other hand, FS and TS had sufficient additive genetic variability to respond to direct selection in Nellore herds. Such genetic changes in temperament are expected to decrease cattle reactivity during handling routines, leading to increased farm profitability (Haskell et al., 2014).

Heifer rebreeding (HR) is considered to be a major problem for primiparous females, especially in tropical countries (Boligon et al., 2012). Heifers usually face considerable challenges after their first calving, mainly due to the combination of harsh environmental conditions and high nutritional demands from growth, lactation and development of the subsequent pregnancy. The rate of HR success in the present study $(70.8 \%)$ was within the range reported in the literature for the Nellore breed, which ranges from $27.1 \%$ to $70 \%$ (Boligon et al., 2012; Guarini et al., 2015; Terakado et al., 2015). According to Boligon et al. (2012), the HR rate could be increased by extending the resting period between the first and the second calving for heifers that first conceived at 16 months of age.

The posterior mean of heritability estimated for $\mathrm{HR}$ was $0.13 \pm 0.02$, indicating that this trait responds to direct selection in the long-term. The HR heritability was also similar to those previously reported, which range from $0.10 \pm 0.07$ (Mercadante et al., 2003) to $0.18 \pm 0.02$ (Boligon et al., 2012) for Nellore heifers. These values indicate that the direct selection for HR associated with improvement in nutrition status and handling practices will produce desirable improvements in heifer fertility and, in the medium to long-term, economic gains.

Stayability (STAY) is usually defined as a cow's probability of remaining in the herd until a specific age, given that each animal has the first calf around two years of age and one calf per year. As it reflects cow longevity and reproductive performance, STAY is an economically relevant trait that influences farm profitability. The percentage of cows that remained in the studied herd for up to 65 months (41.6\%) was higher than those previously reported for Nellore cows, which range from $28.9 \%$ to $37.64 \%$ (Eler et al., 2014; Silva et al., 2003, respectively).

In the present study, STAY was highly influenced by environmental and non-addictive genetic factors, showing low posterior mean of 
Table 5

Posterior estimates of genetic and phenotypic correlations (mean \pm standard deviation) between temperament (CS, FS, MOV, TS and TEN) and reproductive (STAY and HR) traits.

\begin{tabular}{llll}
\hline \multicolumn{1}{c}{ Trait } & Mean $\pm \mathrm{SD}$ & $95 \% \mathrm{HPD}$ & MC \\
\hline Genetic correlations & & & \\
HR-MOV & $-0.12 \pm 0.16$ & -0.43 to 0.17 & 0.0137 \\
HR-TEN & $-0.06 \pm 0.19$ & -0.44 to 0.33 & 0.0197 \\
HR-CS & $-0.19 \pm 0.21$ & -0.56 to 0.22 & 0.0237 \\
HR-FS & $-0.05 \pm 0.13$ & -0.31 to 0.20 & 0.0070 \\
HR-TS & $-0.13 \pm 0.16$ & -0.44 to 0.17 & 0.0108 \\
STAY-MOV & $-0.08 \pm 0.13$ & -0.34 to 0.18 & 0.0089 \\
STAY-TEN & $-0.21 \pm 0.15$ & -0.50 to 0.08 & 0.0136 \\
STAY-CS & $-0.24 \pm 0.16$ & -0.56 to 0.09 & 0.0145 \\
STAY-FS & $-0.03 \pm 0.11$ & -0.23 to 0.19 & 0.0066 \\
STAY-TS & $-0.08 \pm 0.15$ & -0.35 to 0.24 & 0.0116 \\
Phenotypic correlations & & & \\
HR-MOV & $-0.02 \pm 0.03$ & -0.07 to 0.03 & 0.0004 \\
HR-TEN & $-0.01 \pm 0.03$ & -0.07 to 0.04 & 0.0004 \\
HR-CS & $0.00 \pm 0.03$ & -0.05 to 0.05 & 0.0005 \\
HR-FS & $-0.04 \pm 0.02$ & -0.09 to 0.01 & 0.0004 \\
HR-TS & $-0.09 \pm 0.03$ & -0.14 to -0.04 & 0.0004 \\
STAY-MOV & $-0.05 \pm 0.03$ & -0.11 to 0.01 & 0.0005 \\
STAY-TEN & $-0.02 \pm 0.03$ & -0.08 to 0.04 & 0.0004 \\
STAY-CS & $0.00 \pm 0.03$ & -0.06 to 0.05 & 0.0004 \\
STAY-FS & $-0.07 \pm 0.03$ & -0.12 to -0.01 & 0.0003 \\
STAY-TS & $-0.08 \pm 0.03$ & -0.13 to -0.02 & 0.0004 \\
\hline
\end{tabular}

$\mathrm{SD}=$ standard deviation; $\mathrm{MOV}=$ movement score; $\mathrm{TEN}=$ tension score $\mathrm{CS}=$ crush score; FS = flight speed; TS = temperament score; HR = heifer rebreeding; STAY = stayability; HPD = highest posterior density interval containing $95 \%$ of the observations; $\mathrm{MC}=$ Monte Carlo error. heritability $(0.13 \pm 0.02)$. This result is consistent with Eler et al. (2014) and Guarini et al. (2015) who estimated values of 0.19 and $0.18 \pm 0.02$, respectively, for Nellore herds. Additionally, Silva et al. (2003) estimated heritability for STAY at different ages (5, 6 and 7 years) for Nellore cows and reported $0.12 \pm 0.00,0.12 \pm 0.00$ and $0.17 \pm 0.01$, respectively. On the other hand, Van Melis et al. (2007) reported higher heritabilities for STAY until 5, 6 and 7 years of age $(0.25 \pm 0.02,0.22 \pm 0.03$ and $0.28 \pm 0.03$, respectively) for Nellore cows. Although there is a need to balance generation interval and selection strategies for STAY (Ducrocq et al., 1988), in general, these results suggest that it is possible to promote favorable genetic progress in the longevity of beef cattle as a result of long-term selection.

The posterior means estimates of genetic correlations ranged from low to moderate magnitude (Table 5). The highest (in magnitude) and favorable genetic correlations estimated were between CS with HR and STAY ( $-0.19 \pm 0.21$ and $-0.24 \pm 0.16$, respectively) and between TEN and STAY ( $-0.21 \pm 0.15$ ), indicating that the selection to reduce cattle reactivity inside the squeeze chute and improve temperament will not negatively affect heifer rebreeding index or cows' ability to remain in the herd. The phenotypic correlations were all in low magnitudes (Table 5), corroborating Burrow (2001), Phocas et al. (2006) and Barrozo et al. (2012). Fig. 2 shows the posterior densities of genetic correlations.

While previous studies have reported genetic correlations of temperament traits with reproductive efficiency and sexual precocity measured directly and indirectly in heifers and cows (Burrow, 2001; Phocas et al., 2006; Barrozo et al., 2012; Valente et al., 2015), this is the first study to evaluate the associations of temperament with $\mathrm{HR}$ and STAY. Since both temperament and reproduction are complex phenotypes, caution is required when comparing the results of studies using different indicators for these two traits.

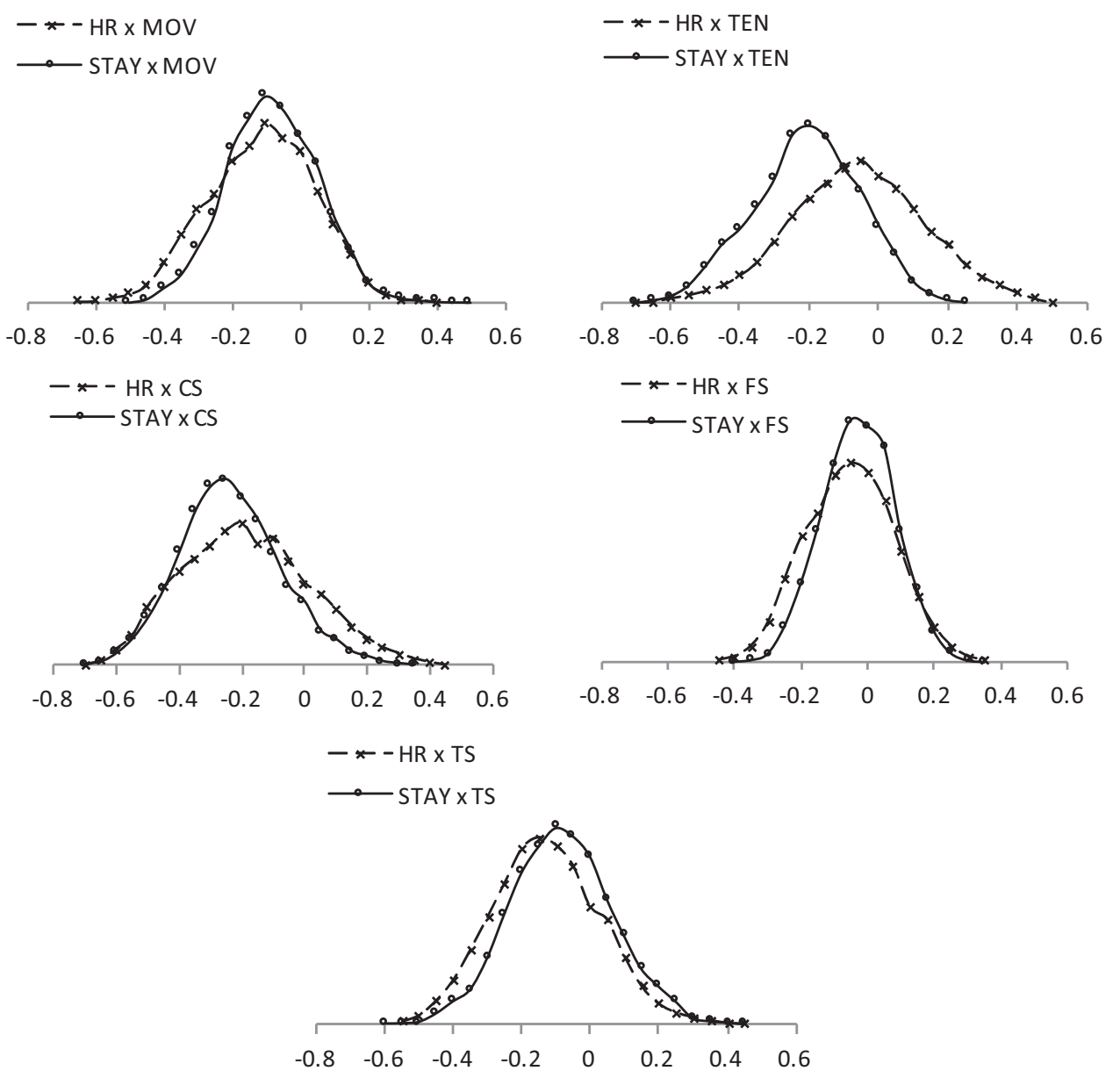

Fig. 2. Posterior distribution of genetic correlations of movement score (MOV), tension score (TEN), crush score (CS), flight speed (FS) and temperament score (TS) with heifer rebreeding (HR) and stayability (STAY) in Nellore cattle. 
In general, the estimated genetic correlations between any temperament and reproduction trait ranged from low to moderate magnitude, and were in the favorable direction (i.e., better temperament is genetically associated with higher sexual precocity and/or fertility). Using a subsample of the dataset analyzed in the present study, Valente et al. (2015) estimated the genetic correlation of MOV, FS and TS with sexual precocity traits measured by age at first calving (AFC), occurrence of precocious pregnancy (OPP) and scrotal circumference (SC), and reported values ranging from $-0.03 \pm 0.16$ (MOV-OPP) to $-0.28 \pm 0.08$ (TS-SC). On the other hand, Barrozo et al. (2012) reported low genetic correlation of TS with AFC (0.06 \pm 0.19$)$ and SC (0.07 \pm 0.07$)$ in Nellore cattle. For the Limousin breed, Phocas et al. (2006) estimated genetic correlations of $-0.32,0.13$ and 0.55 between a docility test and age at puberty, calving ease and heifer fertility, respectively.

Our results suggest that there are no antagonisms between temperament and female reproductive traits related to fertility and longevity. However, the weak relationship also found in other studies and discussed by Haskell et al. (2014) suggests that the temperament and reproductive traits measured directly in heifers and cows are generally independent and controlled by distinct genetic mechanisms with major effects. Thus, we expect that the inclusion of temperament traits in the selection index will, in the long-term, reduce cattle reactivity toward human presence during handling procedures. This is especially important for reproductive management in cow-calf operation farms (e.g. artificial insemination (AI), fixed-time $\mathrm{AI}$ and embryo transfer) as it has the potential to improve pregnancy rates, as previously reported for Nellore cows (Rueda et al., 2015). Additionally, nervous heifers and cows may increase the risk of accidents with both animals and humans, for example, during the first handling of newborn calves (Haskell et al., 2014). Thus, selecting for temperament traits has potential benefits for overall welfare, labor safety and profitability in the livestock industry.

\section{Conclusions}

Estimates of heritability for temperament and reproductive traits measured directly in females have shown that differences in animals' environment (e.g. quality of handling, nutrition status and reproductive strategies) are probably the main cause of variation in those traits. Thus, the inclusion of these traits in Nellore breeding programs would produce genetic gains only in the long-term. Moreover, genetic and phenotypic correlations among these traits show that there is no antagonism of temperament on fertility and longevity of female cattle. Thus, we recommend the inclusion of both traits as selection criteria in Nellore breeding programs in order to obtain satisfactory genetic changes.

\section{Acknowledgements}

This study was part of a master's thesis presented to the graduate program in Genetics and Animal Breeding at the Faculty of Agriculture and Animal Science - Sao Paulo State University (FCAV/UNESP), Jaboticabal, SP, Brazil. Data collection was supported by the São Paulo Research Foundation (Fundação de Amparo à Pesquisa do Estado de São Paulo, FAPESP), Grant 2009/53609-7. We thank Agropecuária Jacarezinho $^{\circledR}$ Ltda. for allowing us to conduct animal evaluations and for their collaboration during data collection.

\section{Conflicts of interest statement}

The authors declare that there is no conflict of interest associated with this publication

\section{References}

Barrozo, D., Buzanskas, M.E., Oliveira, J.A., Munari, D.P., Neves, H.H.R., Queiroz, S.A.,
2012. Genetic parameters and environmental effects on temperament score and reproductive traits of Nellore cattle. Animal 6, 36-40.

Boligon, A.A., Ayres, D.R., Pereira, R.J., Morotti, N.P., Albuquerque, L.G., 2012. Genetic associations of visual scores with subsequent rebreeding and days to first calving in Nellore cattle. J. Anim. Breed. Genet. 129, 448-456.

Burrow, H.M., 2001. Variances and covariances between productive and adaptive traits and temperament in a composite breed of tropical beef cattle. Livest. Prod. Sci. 70, 213-233.

Burrow, H.M., Corbet, N.J., 2000. Genetic and environmental factors affecting temperament of zebu and zebu-derived beef cattle grazed at pasture in the tropics. Aust. J. Agric. Res. 55, 155-162.

Burrow, H.M., Seifert, G.W., Corbet, N.J., 1988. A new technique for measuring temperament in cattle. Aust. Soc. Anim. Prod. 17, 154-157.

DeltaGen, 2016. Sumário de Touros DeltaGen: Brazil. Retrieved on 20 October 2016, from: 〈http://www.deltagen.com.br/sumario_delta_gen.pdf $\rangle$.

Ducrocq, V., Quaas, R.L., Pollak, E.J., Casella, G., 1988. Length of productive life of dairy cows. 2. Variance component estimation and sire evaluation. J. Dairy Sci. 71 3070-3079.

Eler, J.P., Bignardi, A.B., Ferraz, J.B.S., Santana Jr, M.L., 2014. Genetic relationships among traits related to reproduction and growth of Nelore females. Theriogenology $82,708-714$.

Gelfand, A.E., Smith, A.F.M., 1990. Sampling-based approaches to calculating marginal densities. J. Am. Stat. Assoc. 85, 398-409.

Geweke, J., 1992. Evaluating the accuracy of sampling-based approaches to calculating posterior moments. In: Bernardo, J.M., Berger, J.O., David, A.P., Smith, A.F.M. (Eds.), Bayesian Statistics. Clarendon Press, Oxford, pp. 169-193.

Guarini, A.R., Neves, H.H.R., Schenkel, F.S., Carvalheiro, R., Oliveira, J.A., Queiroz, S.A., 2015. Genetic relationship among reproductive traits in Nellore cattle. Animal 9, 760-765.

Haskell, M.J., Simm, G., Turner, S., 2014. Genetic selection for temperament traits in dairy and beef cattle. Front. Genet. 5, 1-18.

Heidelberger, P., Welch, P.D., 1983. Simulation run length control in the presence of an initial transient. Oper. Res. 31, 1109-1144.

Kasimanickam, R., Schroeder, S., Assay, M., Kasimanickam, V., Moore, D.A., Gay, J.M., Whittier, W.D., 2014. Influence of temperament score and handling facility on stress, reproductive hormone concentrations, and fixed time AI pregnancy rates in beef heifers. Reproduct. Domest. Anim. 49, 775-782.

Mercadante, M.E.Z., Packer, I.U., Razook, A.G., Cyrillo, J.N.S.G., Figueiredo, L.A., 2003. Direct and correlated responses to selection for yearling weight on reproductive performance of Nelore cows. J. Anim. Sci. 81, 376-384.

Misztal, I., Tsuruta, S., Strabel, T., Auvray, B., Druet, T., Lee, D.H., 2002. BLUPF90 and related programs (BGF90). In: Proceedings of the 7th World Congress on Genetics Applied to Livestock Production, Montpellier, France, August 2002. Communication no. 28-07.

Phocas, F., Boivin, X., Sapa, J., Trillat, G., Boissy, A., Le Neindre, P., 2006. Genetic correlations between temperament and breeding traits in Limousin heifers. Anim. Sci. 82, 805-811.

Piovezan, U., Cyrillo, J.N.S.G., Paranhos da Costa, M.J.R., 2013. Breed and selection line differences in the temperament of beef cattle. Acta Scientiarum Anim. Sci. 35, 207-212.

Prayaga, K.C., Corbet, N.J., Johnston, D.J., Wolcott, M.L., Fordyce, G., Burrow, H.M., 2009. Genetics of adaptive traits in heifers and their relationship to growth, pubertal and carcass traits in two tropical beef cattle genotypes. Anim. Prod. Sci. 49, 413-425.

Raftery, A.E., Lewis, S.M., 1992. How many iterations in the Gibbs sampler? In: Bernardo, J.M., Berger, J.O., David, A.P., Smith, A.F.M. (Eds.), Bayesian Statistics. Clarendon Press, Oxford, pp. 763-773.

Rueda, P.M., Sant'Anna, A.C., Valente, T.S., Paranhos da Costa, M.J.R., 2015. Impact of the temperament of Nellore cow on the quality of handling and pregnancy rates in fixed-time artificial insemination. Livest. Sci. 177, 189-195.

Sant'anna, A.C., Paranhos da Costa, M.J.R., Baldi, F., Albuquerque, L.G., 2013. Genetic variability for temperament indicators of Nellore cattle. J. Anim. Sci. 91, 3532-3537.

Sant'Anna, A.C., Baldi, F., Valente, T.S., Albuquerque, L.G., Menezes, L.M., Boligon, A.A., Paranhos da Costa, M.J.R., 2015. Genetic associations between temperament and performance traits in Nellore beef cattle. J. Anim. Breed. Genet. 132, 42-50.

Silva, J.A.I.I.V., Eler, J.P., Ferraz, J.B.S., Golden, B.L., Oliveira, H.N., 2003. Heritability estimate for stayability in Nelore cows. Livest. Prod. Sci. 79, 97-101.

Terakado, A.P., Boligon, A.A., Baldi, F., Silva, J.A., Albuquerque, L.G., 2015. Genetic associations between scrotal circumference and female reproductive traits in Nelore cattle. J. Anim. Sci. 93, 2706-2713.

Valente, T.S., Sant'Anna, A.C., Baldi, F., Albuquerque, L.G., Paranhos da Costa, M.J.R., 2015. Genetic association between temperament and sexual precocity indicator traits in Nellore cattle. J. Appl. Genet. 56, 349-354.

Van Melis, M.H., Eler, J.P., Oliveira, H.N., Rosa, G.J.M., Silva, J.A.I.I.V., Ferraz, J.B.S., Pereira, E., 2007. Study of stayability in Nellore cows using a threshold model. J. Anim. Sci. 85, 1780-1786.

Van Tassell, C.P., Van Vleck, L.D., 1996. Multiple-trait Gibbs sampler for animal models: flexible programs for Bayesian and likelihood- based (co)variance component inference. J. Anim. Sci. 74, 2586-2597.

Van Tassell, C.P., Van Vleck, L.D., Gregory, K.E., 1998. Bayesian analysis of twinning and ovulation rates using a multiple trait threshold model and Gibbs sampling. J. Anim. Sci. 76, 2048-2061.

White, K.L., Bormann, J.M., Olson, K.C., Jaeger, J.R., Johnson, S., Downey, B., Grieger, D.M., Waggoner, J.W., Moser, D.W., Weaber, R.L., 2016. Phenotypic relationships between docility and reproduction in Angus heifers. J. Anim. Sci. 94, 483-489. 